\title{
Modular split-type heat pump with compact and silent façade- integrated outdoor unit
}

\author{
William Monteleone ${ }^{1 *}$, Fabian Ochs ${ }^{1}$, Christof Drexel $^{2}$, and Mattias Rothbacher ${ }^{3}$ \\ ${ }^{1}$ University of Innsbruck, Unit for Energy Efficient Building, 6020 Innsbruck, Austria \\ ${ }^{2}$ drexel reduziert $\mathrm{GmbH}, 6900$ Bregenz, Austria \\ ${ }^{3}$ Ingenieurbüro Rothbacher GmbH, 5700 Zell am See, Austria
}

\begin{abstract}
For future buildings (nZEBs according to EPBD) efficient and cost-effective heating systems with a high share of renewable energy are required. Heat pumps (HP) are considered as one of the key technologies in the building sector. However, in particular in high-density housing areas, source exploitation is strongly limited. Accordingly, the market in Austria does not currently provide real alternatives to apartment gas or electric boilers. Split type HPs with low power can be made compact and cost effective and thus offer new possibilities. However, split type HPs represent a real alternative only if the acceptance for them can be improved by means of improved modularity, design, architectural attractive integration in the building envelope and reduced sound emissions. The goal of the Austrian FFG research project FitNeS is the development and optimization of modular split HPs with compact and silent façade-integrated outdoor units. The outstanding features of the concept are a modular design with a high degree of prefabrication and representing a visually and architectonically attractive, economic and sustainable solution for both new constructions and renovations. Different concepts of façade-integrated outdoor units will be developed and evaluated with regard to design, façade construction, accessibility (for maintenance), building physics, efficiency, etc. on the basis of the technical and non-technical boundary conditions.
\end{abstract}

\section{Introduction}

The European Building Performance Directive (EPBD) 2010/31/EU , lastly updated with the Directive 2018/844 [1] of the European Parliament, demands that member countries should reduce greenhouse gas emissions of $40 \%$ by 2030 compared to the emissions in 1990. Moreover, according to the same directive, member States should also commit themselves to reach the goal of a fully decarbonised building stock, currently responsible of about $36 \%$ of the $\mathrm{CO}_{2}$ emissions in the European Union, by 2050. Austria has additionally stated the target of achieving full carbon neutrality by 2040 (10 years earlier than the European target) and $100 \%$ renewable electricity consumption by 2030 [2][3].

Whether this goal can be realistically achieved or not, heat pumps are regarded as a promising solution to successfully reach the decarbonisation of the building sector although their spreading is often hindered by technical difficulties and socio-economic constraints. Especially in densely populated urban environments the source accessibility is limited and air represents the only solution that does not require major construction works (e.g. for groundwater heat pumps).

In renovation cases, compared to new constructions, the source accessibility is even more constrained. In this context, the Austrian market does not currently provide efficient and sustainable alternatives to electric or gas boilers for the supply of heating and/or domestic hot water demand [4], which can be mounted externally with minimal disruptive works in those contexts where a connection to the local district heating network is not possible. On the other hand, split heat pumps already available on the market lack of compactness and reduced sound emissions (no clear limit value is imposed at the national level), while the aesthetics of the outdoor unit is often neglected. Considering also the national goal of phasing out gas-fired heating systems by 2040 [2] and the European goal of reaching a renovation rate of $3 \%$ by 2050 [1] (in Austria still at $0.7 \%$ as of 2018 [3]), a novel architectonically attractive modular split HP has to be developed and optimized with focus on compact design, reduced sound emissions and efficiency by means of CFD analysis, refrigerant cycle simulation and laboratory tests.

\section{Concept}

The research project currently focuses its attention on decentral domestic hot water preparation by means of a mini-split air-to-water heat pump with a rated power of $1500 \mathrm{~W}$, filled with propane (R290) as refrigerant. However, it is not excluded that in the future similar concepts will be applied to space heating and/or cooling. The currently developed design is presented in Fig. 1.

\footnotetext{
* Corresponding author: william.monteleone@uibk.ac.at
} 
To correctly decouple the hot water demand from the supply, a domestic hot water storage (DHWS) is provided. A fresh water station guarantees the heat transfer from the hot technical water available in the storage to drinking water before being delivered to the user. This design choice gives an additional advantage in terms of Legionella treatment. In fact, since water from the storage is not directly delivered to the user, there is no need to occasionally heat it up to above 60 ${ }^{\circ} \mathrm{C}$ to prevent bacterial growth. On the other end, the outdoor unit, housing the evaporator and one or multiple fans, is partially integrated inside the insulation layer of the building. Air flow takes place transversally to the façade.

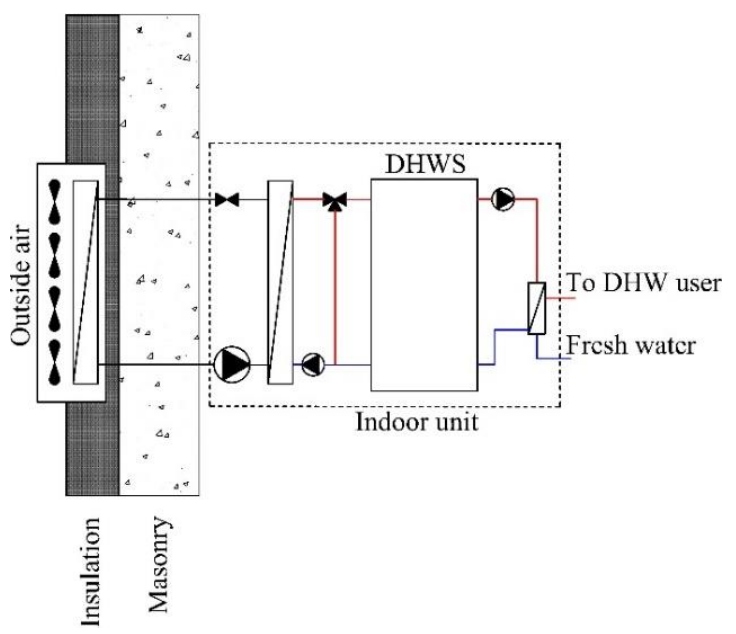

Figure 1. Scheme of the mini-split heat pump supplying hot water to the domestic hot water storage (DHWS). Hot water is then delivered to the user by means of a fresh water station.

Several design variants were evaluated depending on the type of fan, the geometry and the position of the evaporator. The scheme presented in Fig. 2 should give a better overlook on the conceptual framework behind preliminary analyses. Fig. 3 and 4 show in section two possible arrangements in the housing of fans and evaporator inside the outdoor unit. The overhang, which is visible from the exterior (corresponding to the shaded part in fig. 3 and fig. 4), is limited to just $6 \mathrm{~cm}$. An outside view of the façade with the installed outdoor unit is shown in fig. 5. For sake of simplicity, the drawings were reported for the case of one single radial fan.

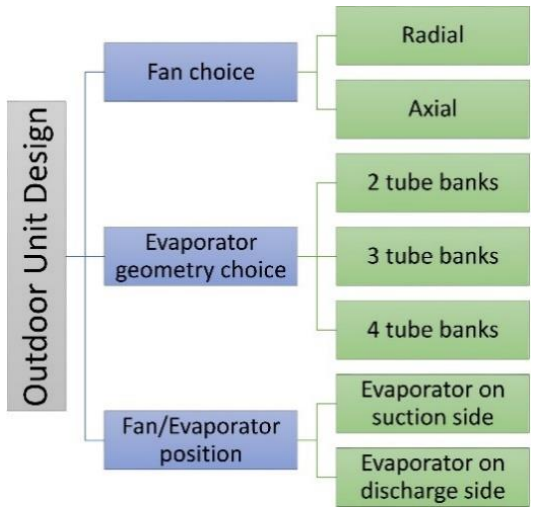

Figure 2. Conceptual framework behind the design and improvement of the outdoor unit used for numerical analyses.

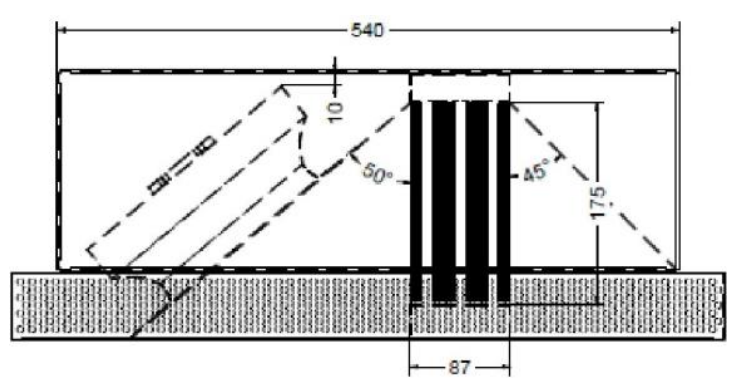

Figure 3. Section of the outdoor unit showing a possible arrangement of the fan and of the evaporator. The evaporator is placed on the suction side of the fan and airflow takes place in a right-left direction, with air being discharged with an angle of $50^{\circ}$ with respect to the façade.

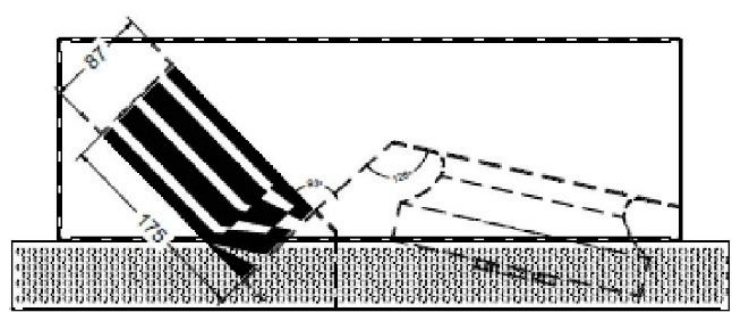

Figure 4. Section of the outdoor unit showing another possible arrangement of the fan and of the evaporator. Airflow takes place in left-right direction, with air being discharged at an angle of about $20^{\circ}$ with respect to the façade.

In Fig. 3 airflow happens from the right to the left of the drawing, with the evaporator mounted vertically, occupying almost the entire height of the outdoor element. Air leaves the outdoor unit with an incidence angle of $50^{\circ}$ related to the façade. The design shown in fig. 4 includes instead an evaporator tilted of an angle of $45^{\circ}$ with respect to the cover. In this case, airflow takes place in a left-right direction, with air being discharged almost tangentially to the façade. In the design variants where a single radial fan is considered, the impeller is either mounted in a central position corresponding to half the height of the evaporator or eccentrically.

The correct positioning of the evaporator with respect to the fans is crucial not only for the overall performance of the refrigerant cycle, but also for the reduction of sound emissions. For example, having the evaporator mounted on the suction side of the fan/s acts as noise damper towards the outside, while ensuring on the other side a good degree of flow homogeneity. In each design variant, in order to protect the fans from rain and snow, the top element of the outdoor unit is accordingly sealed.

Sufficient space is also available, inside the outdoor unit, for the installation of sound insulation material to further reduce sound emissions. A constant speed rotary compressor with a displacement of $12.75 \mathrm{~cm}^{3}$ is used to bring the refrigerant fluid up to the condensation pressure. A plate heat exchanger is used to transfer heat from the condensing mixture to water. On the secondary side of the condenser, water is then delivered at a temperature of $50{ }^{\circ} \mathrm{C}$ to the upper part of the storage. In the startup phase of the heat pump, the diverting valve is closed to prevent cold water from going into the storage. In this case, water circulates in a closed loop 
until the setpoint temperature of $50{ }^{\circ} \mathrm{C}$ is reached. The hot water storage size ranges from 90 to 1501 .

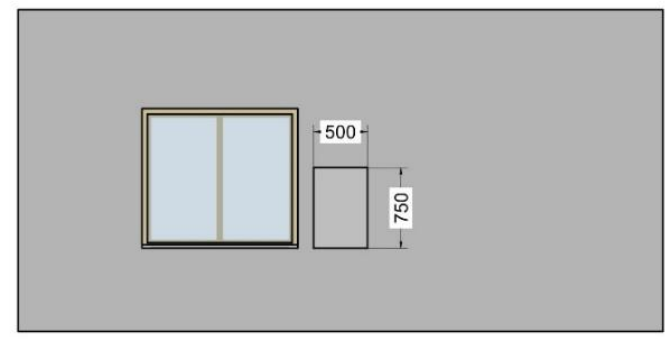

Figure 5. Planar view of the current design of the façade integrated outdoor unit giving an idea of the overall dimensions of the covering panel. Measures are indicated in $\mathrm{mm}$.

\section{Methodology}

To reach the goal of developing an efficient alternative to gas or electric boilers for DHW production, CFD analyses were performed in the predesign phase to optimize the airflow across the outdoor unit. The optimal geometries were then selected following the subsequent criteria:

- Flow homogeneity on the incident evaporator surface (in terms of standard deviation);

- $\quad$ Air-side pressure drop minimization;

- Effect on the overall performance of the refrigerant cycle by means of refrigerant cycle simulations.

Obtaining a possibly homogeneous flow guarantees that the evaporation pressure of the refrigerant stays more or less constant for each refrigerant circuit, whereas highly inhomogeneous flows can have a negative effect on the efficiency of the heat pump.

At first, the calculated flow patterns were obtained with a rated air volume flow of $350 \mathrm{~m}^{3} / \mathrm{h}$ and using a single radial fan with a $220 \mathrm{~mm}$ impeller diameter. Slight improvements in flow homogeneity can be reached by additionally increasing the thickness of the evaporator, which in turn increases the pressure drop. Component level simulations were run to investigate the relationship between evaporator thickness, number of circuits and cooling capacity. Three different geometries of the evaporator have been considered in the analysis:

- $0.70 \times 0.16 \times 0.06 \mathrm{~m}(\mathrm{H} \times \mathrm{L} \times \mathrm{W})$ with 3 tube banks (from now on Geometry A, adopted as benchmark);

- $\quad 1.05$ x 0.16 x $0.04 \mathrm{~m}(\mathrm{H} \times \mathrm{L} \times \mathrm{W})$ with 2 tube banks (from now on Geometry B);

- $0.53 \times 0.16 \times 0.08 \mathrm{~m}(\mathrm{H} \times \mathrm{L} \times \mathrm{W})$ with 4 tube banks (from now on Geometry $\mathrm{C}$ ).

All of the configurations share the same heat transfer area so that an objective comparison among them can be done.

In the end, full refrigerant cycle simulations were performed to assess the influence of the abovementioned configurations on the system efficiency. The results of the full refrigerant cycle simulations, in terms of performance maps, are a necessary input for further dynamic system simulations to investigate the overall primary energy consumption of the heat pump and find possible design inaccuracies. The water consumption profile "M" (according to EN 16147 [5]) was assumed to simulate the domestic hot water demand during the day. Laboratory tests were also performed with a functional model of the outdoor unit of the heat pump to validate fluid-dynamics simulations and investigate the actual electrical power consumption of the fans as well as the sound emissions.

\subsection{CFD modelling}

The theoretically optimal design of the outdoor unit was investigated by means of CFD simulations performed with the software Ansys 19.2. With the purpose of optimising the overall flow, it was decided to approximate the evaporator as a porous fluid subdomain, with defined streamwise and transverse loss coefficients, to replicate the airflow across the microchannels between the fins. Both loss coefficients were calibrated to match the pressure drop observed in the laboratory for Geometry A under the same flow conditions. For each simulation the assumptions presented in Table 1 regarding the boundary conditions were made:

Table 1. Boundary conditions CFD models.

\begin{tabular}{|c|c|}
\hline Location & BC \\
\hline Inlet & Total pressure $=0 \mathrm{~Pa}$ \\
\hline Outlet & Mass flow $=0.12 \mathrm{~kg} / \mathrm{s}$ \\
\hline Walls & No Slip Wall \\
\hline Evaporator & $\begin{array}{l}\text { Streamwise loss coeff. }=363 \mathrm{~m}^{-1} \\
\text { Transverse loss coeff. }=3630 \mathrm{~m}^{-1}\end{array}$ \\
\hline
\end{tabular}

Each simulation uses a standard $k$ - $\varepsilon$ turbulence model. This choice is justified by the extensive adoption of this type of turbulence model in problems involving constrained flow around finned geometries or baffles and in its ability to provide more accurate results compared to other turbulence models [6].

In order for a simulation to be retained successful, the root mean square of the residual error should reach a value of $1 \mathrm{e}-6$. When this happens, the simulation is considered as fully converged. The following analyses and evaluations will always refer to fully converged simulation models.

A preliminary selection of plausible flow geometries was performed on the basis of standard deviation (\%) in relationship to the average flow velocity in the simulated model defined as (eq. (1)):

$$
\sigma_{\%, a v g}=\frac{\sigma_{a v g}}{v_{\text {avg }}} \cdot 100[\%]
$$

Where $\sigma_{\text {avg }}$ represents the standard deviation of the average absolute velocity and $v_{\text {avg }}$ the average absolute velocity in the model.

This choice allows to characterize analytically flow homogeneity on the incident surface of the evaporator, which also affects the refrigerant cycle performance. Tab. 2 illustrates the variants evaluated in the first 
preliminary CFD analysis with indications on the type of fan taken into consideration, the number and the position of the evaporator with respect to the fan/s. The optimization in variants 2 and 3 consists in a smoother inlet geometry leading to the evaporator.

Table 2. Geometric variants simulated in the first preliminary CFD analysis.

\begin{tabular}{|c|c|c|c|}
\hline $\begin{array}{c}\text { Variant } \\
\text { name }\end{array}$ & Type of fan & $\begin{array}{c}\text { Number } \\
\text { of fans }\end{array}$ & $\begin{array}{c}\text { Position of the } \\
\text { evaporator }\end{array}$ \\
\hline Variant 1 & Axial/Radial & $\begin{array}{c}1 / 4(\mathrm{ax}) \\
1(\mathrm{rad})\end{array}$ & Suction/discharge \\
\hline Variant 2 & Axial/Radial & $\begin{array}{c}4(\mathrm{ax}) \\
1(\mathrm{rad})\end{array}$ & Suction/discharge \\
\hline $\begin{array}{c}\text { Variant 2 } \\
\text { optimized }\end{array}$ & Radial & 1 & Suction \\
\hline Variant 3 & Radial & 1 & Suction \\
\hline $\begin{array}{c}\text { Variant 3 } \\
\text { optimized }\end{array}$ & Radial & 1 or 2 & Suction \\
\hline Variant 4 & Radial & 1 & Suction \\
\hline Variant 5 & Radial & 1 & Suction \\
\hline
\end{tabular}

The reason behind the choice of multiple smaller axial fans rather than a single one is related to the different working principle of axial fans compared to radial fans and to the constraint of keeping an air volume flow of $350 \mathrm{~m}^{3} / \mathrm{h}$.

Fig. 6 and 7 show a couple of the geometrical variants indicated in Tab. 2. For sake of simplicity, the geometries for only one type of fan are reported. Variant 2 features four axial fans in line and a more elongated evaporator compared to variant 1 , which exhibits two rows of two axial fans and a more square-shaped evaporator. In both fig. 6 and 7 the evaporator is placed on the suction side of the fans.

In some cases, in order to correctly reproduce the turbulent behaviour of outdoor air when it is entering the outdoor unit, an air control volume was added to the model and given a medium turbulence intensity of 5\%. Such control volume can be seen for example in fig. 7 .

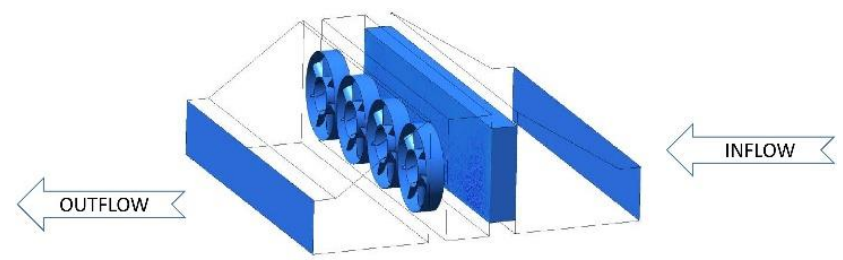

Figure 6. Variant 2 with four inline axial fans and a slimmer evaporator.

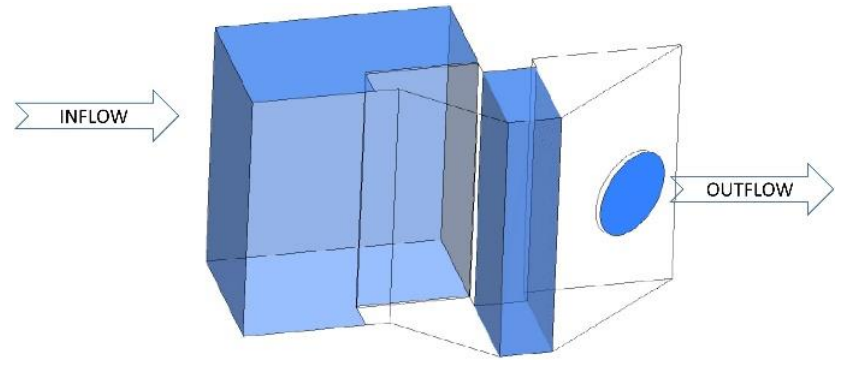

Figure 7. Variant 5 with a single radial fan and a more compact evaporator. Inlet air control volume is also depicted.
In the case of radial fans, a correct positioning of the impeller is crucial to avoid inhomogeneous flow conditions. For this reason, frequently in simulations the fan was considered to be placed at middle height of the outdoor unit (as in fig. 7). Nonetheless eccentric flow configurations were investigated and the standard deviation assessed.

Typical outputs like those shown in fig. 8 and 9 were calculated, as a result of the CFD simulations and their results visualized in terms of streamlines. In order to simulate the rotation of the axial fans, a local reference system was defined for each fan and given a defined rotational speed. Possible flow interferences between fans were also investigated into detail.

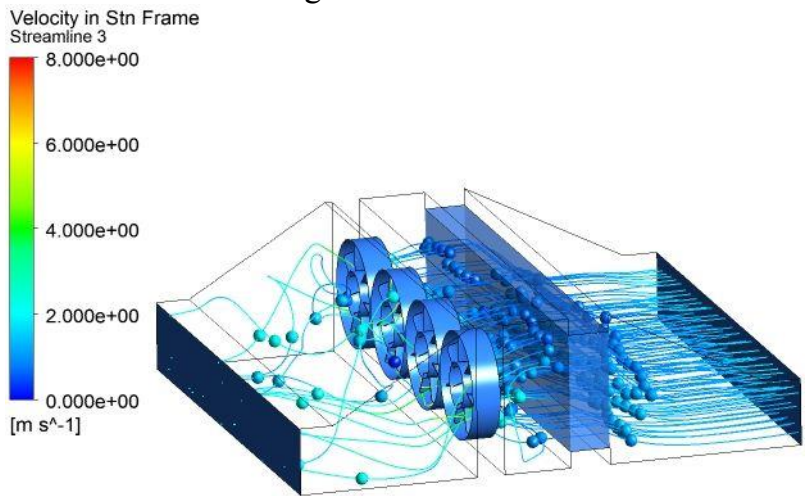

Figure 8. CFD results of the simulation of variant 2 in terms of streamlines.

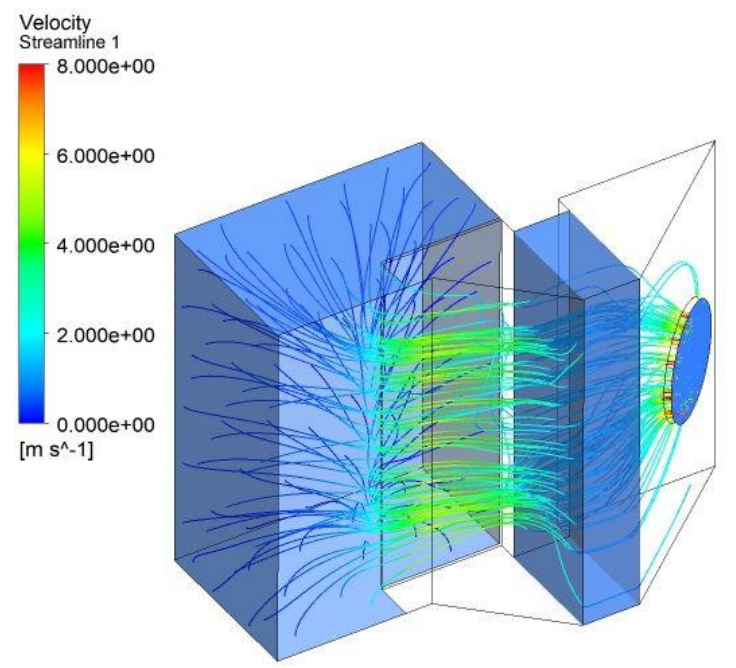

Figure 9. CFD results of the simulation of variant 5 in terms of streamlines.

\subsection{Component-level simulation}

In order to find the proper size of the evaporator with respect to pressure drop and cooling capacity, a model of a real scale evaporator was built in the software CoilDesigner [7]. As previously noted, three geometries with different sizes but equal overall heat transfer area were evaluated. Geometry "A" was used initially as benchmark and compared to the two alternatives " $\mathrm{B}$ " and "C". Each simulation requires the exact piping of the evaporator to be known, as well as the position of inlet and outlet pipes. CFD velocity profiles can be also 
given as input to the simulation to assess the effect of inhomogeneous flow on the component heat exchange. The influence of asymmetric refrigerant circuits was also investigated. For sake of simplicity, the initial simulations were run with $10{ }^{\circ} \mathrm{C}$ inlet air temperature and dry air. In later stages of the analysis, however, the latent load of the evaporator has to be taken also into consideration, usually accounting for $20 \%$ of the total load. A first post-processing of the results was done concerning the total pressure drop of the evaporator. Further considerations of the simulation outputs, in terms of overall heat exchange coefficients UA [W/K] or cooling capacity [W] were done subsequently after integrating the component simulation into more detailed refrigerant cycle models.

\subsection{Refrigerant cycle simulation}

Component-level simulation alone is not sufficient to evaluate the performance of the heat pump with varying airflow conditions. A full refrigerant cycle simulation is needed in this case. For this purpose two numerical models were developed. At first, a simple 4-components refrigerant cycle model was built in MATLAB to get a first quantitative indications about the "best" evaporator geometry. The results of the evaporator-level simulation were exported and integrated in the analysis as well. Initial evaluations were performed assuming an uniform flow profile. Empirical isentropic and volumetric efficiency curves were implemented, in form of polynomials, inside the compressor model to deduce the refrigerant mass flow (eq. (2)):

$$
\dot{m}_{\text {ref }}=\eta_{v o l} \frac{n}{60} D_{c} \rho_{\text {ref,suction }}[\mathrm{kg} / \mathrm{s}]
$$

where $\eta_{v o l}$ is the volumetric efficiency, $n$ the rotational speed of the compressor in $[\mathrm{rpm}], D_{c}$ the maximum displacement of the compressor in $\left[\mathrm{m}^{3}\right]$ and $\rho_{\text {ref,suction }}$ the density of the refrigerant vapour on the suction side of the compressor in $\left[\mathrm{kg} \mathrm{m}^{-3}\right]$. On the other hand, the condenser was assumed to be an ideal heat exchanger. The boundary conditions shown in Table 3 were imposed for the refrigerant cycle analysis.

Table 3. Boundary conditions of refrigerant cycle simulations in MATLAB.

\begin{tabular}{|c|c|c|}
\hline Physical quantity & Value & Unit \\
\hline Air volume flow & 350 & $\mathrm{~m}^{3} / \mathrm{h}$ \\
\hline Air inlet temperature & 10 & ${ }^{\circ} \mathrm{C}$ \\
\hline Mass flow water & 0.072 & $\mathrm{~kg} / \mathrm{s}$ \\
\hline Water inlet temperature & 45 & ${ }^{\circ} \mathrm{C}$ \\
\hline
\end{tabular}

In each simulated case the model is set to converge for a rated condenser power of $1.5 \mathrm{~kW}$.

Additionally, a simplified model for the calculation of heat losses through the shell of the compressor was adopted.

No equation has been currently implemented to calculate the required refrigerant charge. As outcome, the model delivers the full characterization of the refrigerant cycle in terms of condensation and evaporation pressures, condenser power, compressor electrical power consumption and finally COP. In order to run the model, the generation of look-up tables coming from the previous component-level simulations is needed, making it a time-consuming two-step process. Thus, the goal of this model is not forecasting in absolute terms the performance of the heat pump, but rather to have an initial comparison among different evaporator geometries. A more extensive analysis was performed in the commercial software $V a p C y c$ [8] that included not only the usual four components (compressor, condenser, expansion valve and evaporator), but also the pipes connecting them. In this case, the component-level simulations of the evaporator were directly integrated into the software without the need to execute additional simulations. Ten-coefficients polynomials extracted from the manufacturer data were used this time in the compressor model to define a correlation between condensation temperature, evaporation temperature, refrigerant mass flow and electrical power consumption. Finally, a plate heat exchanger with a size of $1.5 \mathrm{~kW}$ at A7W35 was chosen from a database of condensers provided by the manufacturer.

The boundary conditions explained in Tab. 3 apply as well to this more refined model, with the following additional convergence criteria:

- $\quad$ Superheating degree $\Delta T_{\text {super }}=8 \mathrm{~K}$;

- $\quad$ Subcooling $\Delta T_{\text {sub }}=2 \mathrm{~K}$.

\subsection{Laboratory measurements}

In parallel to simulation work, laboratory measurements were performed in the acoustical test rig of the University of Innsbruck to validate the results of the CFD simulations and take into consideration as well sound emission level and electrical power consumption of the fans. In order to impose different pressure conditions upstream of the fans, a PI controlled ventilation flap with $0-10 \mathrm{~V}$ input was used. To keep the pressure difference across the fans constant and to enhance measurement replicability, pressure is equalized to zero downstream with the use of a support ventilator. The rotational speed of the fans is controlled via a PWM module for the case of axial fans and via a $0-10 \mathrm{~V}$ input signal for the radial fan. When acoustical measurements have to be performed, the measurement channel downstream of the fans is opened, the support fan shut down and a microphone is inserted. A continuous measurement with a minimal duration of 45 seconds is then executed. To ensure that multiple body reflections are not disturbing the sound measurement, noise-absorbing panels are mounted in hemispherical fashion around the operator. The measurement layout is shown in fig. 10 and 11. Pressure sensors are installed before and after the fans for control purposes. Volume flow measurement is performed with the help of a hot film anemometer at a distance of approximately ten times the diameter of the pipe downstream of the fans. 


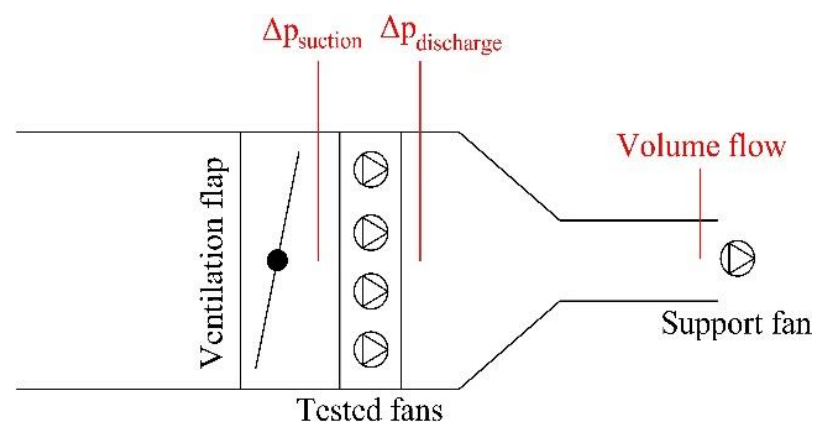

Figure 10. Measurement lab layout for the testing of electrical power consumption and sound emissions. Measurement points for indicated quantities are shown in red.

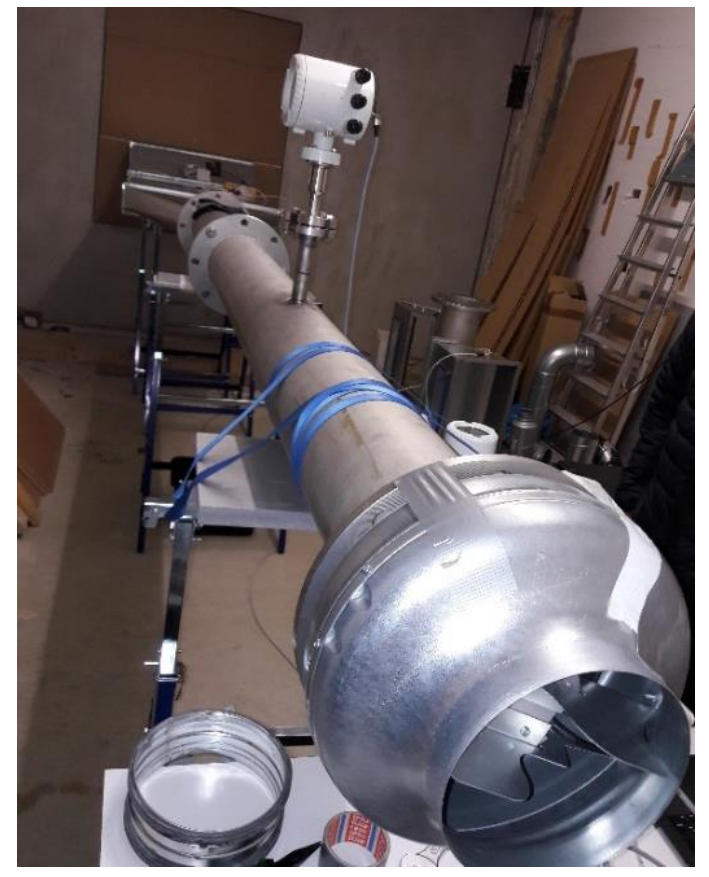

Figure 11. Measurement channel for the testing of electrical power consumption and sound emissions. The volume flow measurement takes place approximately at a distance of 10 times the channel diameter downstream of the fans.

Both acoustical and electrical measurements were performed for the configurations illustrated in the measurement matrix shown in Table 4.

Table 4. Measurement matrix for the determination of fan power consumption and

\begin{tabular}{|c|c|c|}
\hline Fan type & $\begin{array}{c}\dot{V} \\
{\left[\mathbf{m}^{3} / \mathbf{h}\right]}\end{array}$ & $\begin{array}{c}\text { Upstream imposed } \Delta p \\
{[\mathrm{~Pa}]}\end{array}$ \\
\hline \multirow{4}{*}{$\begin{array}{c}4 \text { Inline } \\
\text { Axial } \\
\text { Fans }\end{array}$} & 250 & \multirow{4}{*}{$0 \ldots 5 \ldots 15 \ldots(30)$} \\
\hline & 350 & \\
\hline & 500 & \\
\hline & 650 & \\
\hline \multirow{4}{*}{$\begin{array}{c}\text { Single } \\
\text { Radial } \\
\text { Fan }\end{array}$} & 250 & \multirow{4}{*}{$0 \ldots 5 \ldots 15 \ldots 30 \ldots 45 \ldots 70$} \\
\hline & 350 & \\
\hline & 500 & \\
\hline & 650 & \\
\hline
\end{tabular}

Due to the working principle of axial fans itself, measurements with an upstream imposed pressure drop of $30 \mathrm{~Pa}$ were not always possible for every volume flow. In those cases, the measurement was performed at the maximum reachable pressure drop without incurring into flow blockage.

\section{Results}

\subsection{Results CFD simulations}

The simulation and comparison of the above described geometrical variants delivered the following results (Tab. 5 and 6), in terms of total pressure drop and standard deviation on average velocity.

Table 5. Results of the CFD evaluation and comparison of geometrical variants based on standard deviation.

\begin{tabular}{|c|c|c|c|}
\hline $\begin{array}{l}\text { Variant } \\
\text { name }\end{array}$ & $\begin{array}{c}\text { Fan } \\
\text { configuration }\end{array}$ & $\begin{array}{c}\text { Evaporator } \\
\text { position }\end{array}$ & $\sigma[\%]$ \\
\hline \multirow{4}{*}{ Variant 1} & \multirow{2}{*}{$\begin{array}{l}4 \text { axial fans } \\
\text { (not inline) }\end{array}$} & Suction & 56.3 \\
\hline & & Discharge & 50.6 \\
\hline & \multirow{2}{*}{1 radial fan } & Suction & 80.2 \\
\hline & & Discharge & 90.4 \\
\hline \multirow{3}{*}{ Variant 2} & \multirow{2}{*}{$\begin{array}{l}4 \text { axial fans } \\
\text { (inline) }\end{array}$} & Suction & 7.1 \\
\hline & & Discharge & 23.9 \\
\hline & 1 radial fan & Suction & 10.5 \\
\hline $\begin{array}{l}\text { Variant } 2 \\
\text { optimized }\end{array}$ & 1 radial fan & Suction & 7.1 \\
\hline Variant 3 & 1 radial fan & Suction & 27.7 \\
\hline \multirow{2}{*}{$\begin{array}{r}\text { Variant } 3 \\
\text { optimized }\end{array}$} & 1 radial fan & \multirow{2}{*}{ Suction } & 26.7 \\
\hline & 2 radial fans & & 21.2 \\
\hline Variant 4 & 1 radial fan & Suction & 16.7 \\
\hline Variant 5 & 1 radial fan & Suction & 13.7 \\
\hline
\end{tabular}

\subsection{Refrigerant cycle simulation results}

The different alternatives for the evaporator's geometry were simulated with the developed MATLAB refrigerant cycle model and compared against each other. The preliminary results of the analysis are shown in Table 6.

Table 6. Results of the preliminary refrigerant cycle simulations with the simplified model for geometries "A", "B", "C of the evaporator.

\begin{tabular}{|c|c|c|c|}
\hline Evaporator geometry & A & B & C \\
\hline Superheating $[\mathrm{K}]$ & 9.3 & 10.2 & 9.8 \\
\hline Subcooling $[\mathrm{K}]$ & 3.9 & 4.5 & 2.7 \\
\hline $\begin{array}{c}\text { Refrigerant mass flow } \\
{[\mathrm{kg} / \mathrm{s}]}\end{array}$ & 0.0041 & 0.0041 & 0.0041 \\
\hline$p_{\text {evap }}[\mathrm{bar}]$ & 3.9 & 4.0 & 3.9 \\
\hline$p_{\text {cond }}[\mathrm{bar}]$ & 17.9 & 17.9 & 17.9 \\
\hline Condenser power $[\mathrm{kW}]$ & 1.50 & 1.49 & 1.49 \\
\hline Air-side $\Delta p[\mathrm{~Pa}]$ & 6.0 & 1.9 & 14.0 \\
\hline
\end{tabular}

After an initial investigation aimed to evaluate the possible influence on the refrigerant cycle of different evaporator geometries, the more detailed $V a p C y c$ model was used to run a parametric analysis with varying inlet air temperature and water inlet temperature. The results for the condenser power, the electrical power consumption and the COP are reported in fig. 12 to 14 . 


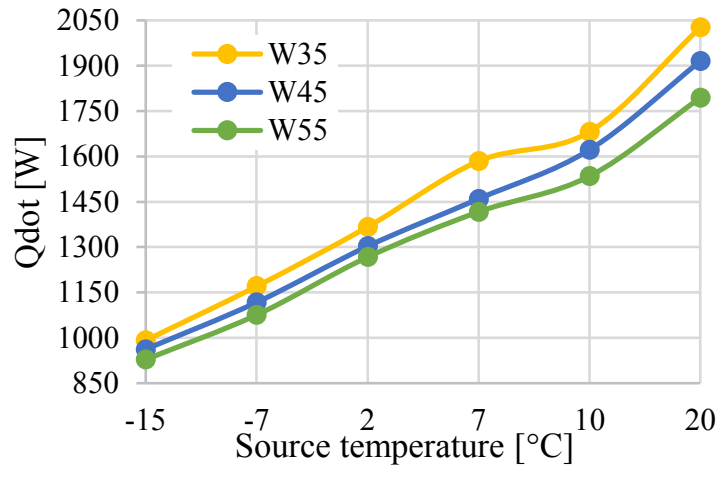

Figure 12. Variation of the simulated condenser power in $[\mathrm{W}]$ depending on source and sink temperatures at uniform flow conditions.

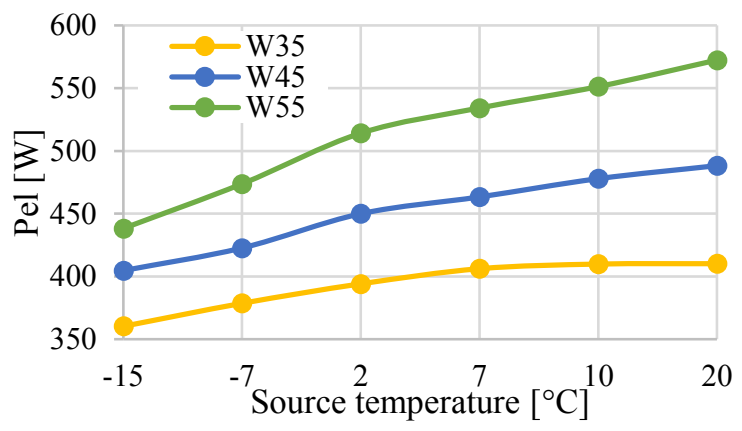

Figure 13. Variation of the simulated electric power consumption in $[\mathrm{W}]$ of the compressor depending on source and sink temperatures at uniform flow conditions.

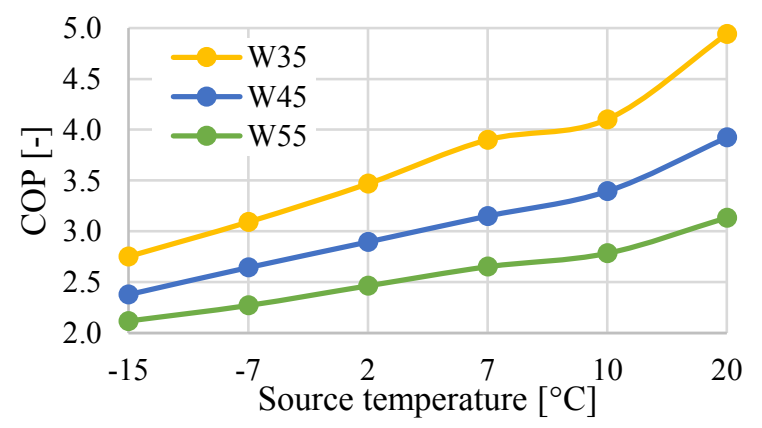

Figure 14. Variation of the COP depending on source and sink temperatures at uniform flow conditions.

\subsection{Laboratory measurements results}

In the acoustical test rig of the University of Innsbruck, the electrical power consumption and the sound emission level of axial and radial fans were measured and compared. The tests were performed with an air volume flow ranging from 250 to $650 \mathrm{~m}^{3} / \mathrm{h}$ and an upstream imposed pressure drop (with the use of a ventilation flap) of 0 to $70 \mathrm{~Pa}$ (whenever possible). Fig. 19 and 20 report only the results of the measurements performed at 250 and $350 \mathrm{~m}^{3} / \mathrm{h}$. In particular, the latter was defined as design air volume flow in the development process while the first one was taken into account for the evaluation of the possible advantages in adopting a lower air volume flow. Higher air volume flows are unlikely to happen in the standard operation of the heat pump.

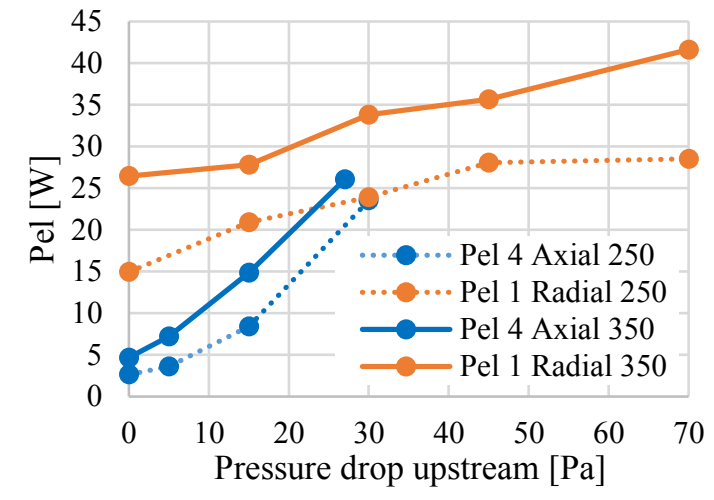

Figure 15. Variation of the measured electrical power consumption of four axial fans or a single radial fan. The measurements were performed at 250 and $350 \mathrm{~m}^{3} / \mathrm{h}$.

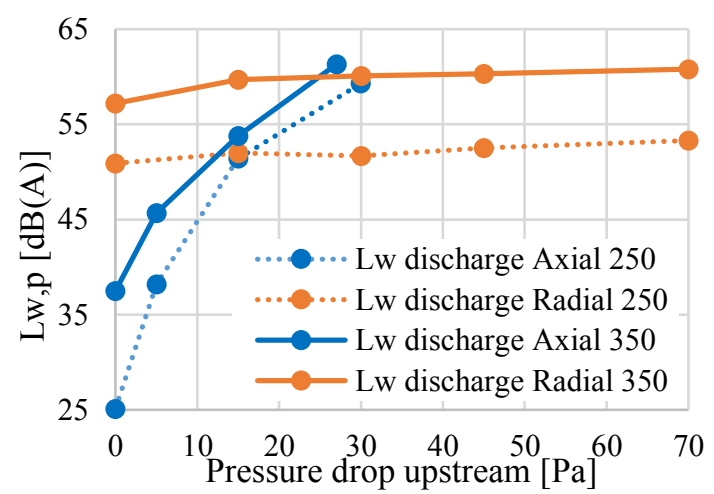

Figure 16. Variation of the measured sound emission level of four axial fans or a single radial fan. The measurements were performed at 250 and $350 \mathrm{~m}^{3} / \mathrm{h}$.

\section{Discussion}

From an initial analysis of the results of the CFD simulations, it was possible to point out the geometrical variants that exhibit a too high standard deviation and thus need to be excluded from further developments. A level of $15 \%$ of standard deviation was considered to be good while a value of less than $10 \%$ was regarded as excellent. According to these assumptions, the variants 1 and 3 showed a highly inhomogeneous flow pattern and for this reason were excluded from future design choices. Promising results in terms of homogeneity were obtained from variant 2, with or without an optimized inlet geometry and from variant 4 and 5. In general, as already mentioned, the positioning of the evaporator on the suction side of the fan/s not only helps in reducing sound emission to the ambient but also gives additional improvements in the overall flow pattern acting as a flow straightener.

On the other hand, the preliminary refrigerant cycle simulations indicated no clear advantages or disadvantages in the refrigerant cycle performance due to different adopted evaporator geometries, also because of the choice of equal heat transfer area. However, if the system efficiency is considered, geometry "B" exhibits a much lower pressure drop of $1.9 \mathrm{~Pa}$, compared to the 6.0 Pa of geometry " $\mathrm{A}$ " and the $14.0 \mathrm{~Pa}$ of geometry 
"B", leading to a reduced electrical power consumption of the fan/s.

The results of the finer refrigerant cycle simulations in $V a p C y c$ revealed instead a limited sensibility of the model to varying heat sink conditions (i.e. water outlet temperature). Considering for example an inlet air temperature of $20^{\circ} \mathrm{C}$, the condenser power (as shown in fig. 12) delivered by the heat pump with an outlet water temperature of $35^{\circ} \mathrm{C}$ is only about $100 \mathrm{~W}$ higher than the power delivered at $45{ }^{\circ} \mathrm{C}$ water temperature. This difference becomes even thinner considering lower air temperatures such as $-15{ }^{\circ} \mathrm{C}$. This behaviour is not observed however in the performance maps of the electrical power consumption (at constant rpm) of the compressor. In this case instead, a change in slope of the electric power consumption curve can be noted at air temperatures lower than $2{ }^{\circ} \mathrm{C}$. This might imply a less finer tuning of the refrigerant cycle model for temperatures below the freezing point or a limited applicability of the manufacturer polynomials in such range. As a result, the electrical power consumption of the compressor may be underestimated and lead to incorrect evaluations. For example, an unrealistic COP of 2.1 is obtained for A-15W55.

Finally, the laboratory measurements suggested that it might be more convenient, in terms of electrical power consumption, to operate axial fans if the overall pressure drop on the suction side of the fans does not surpass 25 $\mathrm{Pa}$ in the case of $350 \mathrm{~m}^{3} / \mathrm{h}$ or $30 \mathrm{~Pa}$ for $250 \mathrm{~m}^{3} / \mathrm{h}$. However, if also the sound emissions are considered in parallel, a maximum pressure drop of $15 \mathrm{~Pa}$ must be ensured in order to maintain the sound level lower than the one of a single radial fan. If a higher pressure drop is observed in the channel, the axial fans need to rotate at almost full rotational speed to keep the same volume flow and their sound emissions become comparable to those of the radial fan. In this region, the choice of a radial fan would be more favourable. Though showing slightly higher sound emission levels than a single radial fan in the same conditions, the configuration with 4 axial fans and an air volume flow of $250 \mathrm{~m}^{3} / \mathrm{h}$ would allow the fans to operate in an (electrically) efficient way up to $30 \mathrm{~Pa}$, thus giving an additional safety margin with respect to frost formation. This configuration would of course require additional sound reduction measures to be undertaken.

\section{Conclusions}

A novel micro-split heat pump for domestic hot water purposes is being developed at the University of Innsbruck through extensive simulation and laboratory work. Fluid-dynamics simulations helped to restrict the pool of the possible geometries of the outdoor unit based on pressure drop and flow pattern. A couple of geometrical variants were excluded from further analyses while the remaining ones remain all plausible. More detailed refrigerant cycle simulations will be needed to quantify the influence on the overall performance of the heat pump following slightly different flow patterns. CFD simulations have to be extended also to an alternative geometry of the evaporator (geometry "B"). The causes of the poor tuning of the refrigerant cycle model developed in $V a p C y c$ have to be further investigated and might be related to the limited applicability of the manufacturer's polynomials used to calculate the refrigerant mass flow and the electrical power consumption of the compressor. In this case, a solution could be to derive experimentally such curves by testing the compressor in the laboratory.

To conclude, electrical and acoustical measurements indicate an advantage in the choice of 4 axial fans versus a single radial fan for pressure drops until $15 \mathrm{~Pa}$, if operated at $350 \mathrm{~m}^{3} / \mathrm{h}$ or until $30 \mathrm{~Pa}$ if run at $250 \mathrm{~m}^{3} / \mathrm{h}$. In the latter case, additional sound reduction measures have to be considered to compensate for the slightly higher sound emission levels. A final choice will be made in the future based also on the adopted de-icing strategy, which in turn affects the maximum allowed pressure drop in the channel.

This work is part of the FFG project FitNeS within the "Stadt der Zukunft" research program.

\section{References}

[1] Directive (EU) 2018/844 of the European Parliament and of the Council of 30 May 2018 amending Directive 2010/31/EU on the energy performance of buildings and Directive 2012/27/EU on energy efficiency, L 156/75, June 2018.

[2] Bundesministerium für Nachhaltigkeit und Tourismus, Bundesministerium für Verkehr, Innovation und Technologie, “\#mission2030 Die österreichische Klima- und Energiestrategie", May 2018.

[3] IEA, “Austria 2020”, May 2020, https://www.iea.org/reports/austria-2020.

[4] Bundesministerium für Klimaschutz, Umwelt, Energie, Mobilität, Innovation und Technologie (BMK), "Innovative Energietechnologien in Österreich Marktentwicklung 2019“, 14/2020, May 2020.

[5] UNI EN 16147, "Heat pumps with electrically driven compressors - Testing, performance rating and requirements for marking of domestic hot water units".

[6] C. Abeykoon, "Compact heat exchangers Design and optimization with CFD," Int. J. Heat Mass Transf., vol. 146, p. 118766, 2020, doi: 10.1016/j.ijheatmasstransfer.2019.118766.

[7] H. Jiang, V. Aute, and R. Radermacher, "CoilDesigner: a general-purpose simulation and design tool for air-to-refrigerant heat exchangers," Int. J. Refrig., 2006, doi: 10.1016/j.ijrefrig.2005.09.019.

[8] D. H. Richardson, H. Jiang, D. Lindsay, and R. Radermacher, "Optimization of vapor compression systems via simulation," Int. Refrig. Air Cond. Conf., 2002. 